\title{
Differentiating Entamoeba histolytica, Entamoeba dispar and Entamoeba moshkovskii using nested polymerase chain reaction (PCR) in rural communities in Malaysia
}

\author{
Romano Ngui, Lorainne Angal, Siti Aminah Fakhrurrazi, Yvonne Lim Ai Lian, Lau Yee Ling, Jamaiah Ibrahim \\ and Rohela Mahmud*
}

\begin{abstract}
Background: In this study, a total of 426 human faecal samples were examined for the presence of Entamoeba histolytica, Entamoeba dispar, Entamoeba moshkovskii infection via a combination of microscopic examination and nested polymerase chain reaction (PCR) targeting 16S ribosomal RNA of Entamoeba species.

Methods: Faecal sample were collected from 426 participants in five rural villages in Peninsular Malaysia. The faecal samples were processed by direct wet smear and formalin ethyl acetate concentration technique followed by iodine staining and examined via microscopy for the presence of Entamoeba species and other intestinal parasites.

Microscopically positive samples for Entamoeba species cysts were further characterized using a Nested Polymerase Chain Reaction (Nested-PCR) targeting 16S-like ribosomal RNA gene. The data entry and analysis was carried out using the SPSS software (Statistical Package for the Social Sciences) program for Windows version 17 (SPSS, Chicago, IL, USA).

Results: Based on single faecal examination, overall prevalence of Entamoeba infection was 17.6\% (75/426). Females (19.1\%) were more commonly infected compared to males (15.9\%). Comparison by age groups showed that adults (23.9\%) had higher infection rates than children (15.3\%). The PCR results showed that 52 out of 75 microscopy positive samples successfully generated species-specific amplicons. The infection with $E$. histolytica $(75.0 \% ; 39 / 52)$ was the most common, followed by E. dispar (30.8\%; 18/52) and E. moshkovskii (5.8\%; 3/52). Of these, 33 (63.5\%) were shown to contain only E. histolytica, 10 (19.2\%) contained E. dispar and 3 (5.8\%) contained only E. moshkovskii. Mixed infection with E. histolytica and E. dispar was found in $6(11.5 \%)$ samples.

Conclusions: The present study essentially emphasized the benefit of molecular techniques in discriminating the pathogenic Entamoeba species from the non-pathogenic for accurate diagnosis and better management of amoebiasis. The presence of E. moshkovskii is of great public health concern as it was the first time it has been reported in Malaysia.
\end{abstract}

\section{Background}

The genus Entamoeba comprises six species, namely Entamoeba histolytica, E. dispar, E. moshkovskii, E. coli, E. hartmanni and $E$. polecki that live in the human intestinal lumen. Infections with Entamoeba species can result in either a harmless colonization of the intestine or invasion of the colonic wall and damage of other host tissues such as liver, lung and brain. Most of the Entamoeba species are

\footnotetext{
*Correspondence: rohela@ummc.edu.my

Department of Parasitology, Faculty of Medicine, University of Malaya, 50603, Kuala Lumpur, Malaysia
}

commensal parasites and do not cause human disease. Amoebiasis which is caused by Entamoeba histolytica is a global health problem as it is responsible for more than 100,000 deaths per year and is the second leading cause of global death due to protozoa after malaria [1-3]. Major symptoms of amoebiasis are abdominal pain, diarrhea, nausea, vomiting and flatulence. This infection is more preponderant in children compared to adults [4] and is commonly found in tropical and subtropical areas.

It has been reported that $10 \%$ of the world's population are infected with Entamoeba species, in which pathogenic 
E. histolytica constitute $10 \%$ of these infections and the remaining $90 \%$ are infected by non-pathogenic E. dispar [5]. However, a recent study highlighted the existence of another species of Entamoeba known as E. moshkovskii which can also cause infection among humans [6]. E. histolytica, E. dispar and E. moshkovskii are morphologically identical but are different biochemically and genetically [6-8]. Although a previous study showed E. moshkovskii to be a non-pathogenic parasite, intestinal symptoms including diarrhea and other gastrointestinal disorders in individuals infected with this species have been reported [8-10]. This, however, has been rebutted by Al-Harthi and Jamjoon (2007) [11] who claimed that E. moshkovskii has never been associated with any disease. This may indicate that perhaps humans are a true host for this putatively free-living amoeba and are not just transiently infected. Therefore, the true prevalence of E. dispar and E. moshkovskii infections need to be investigated in order to determine their significant pathogenic potential in humans.

Traditionally, Entamoeba infections are diagnosed through microscopic examination of fresh or fixed faecal samples. However, very often E. histolytica cysts and trophozoites cannot be morphologically differentiated from E. dispar and E. moshkovskii through microscopic examination. Only when ingested red blood cells are present in trophozoites of E. histolytica, the ability to distinguish them from those of E. dispar and E. moshkovskii becomes easier. Recently, sensitive and specific serological and molecular techniques that are able to distinguish $E$. histolytica from $E$. dispar have been developed [10,12-20]. These include the detection of E. histolytica antigen using an enzyme-linked immunosorbent assay (ELISA) [16,17,19], the detection of E. histolytica by monoclonal antibodies of E. histolytica that specifically recognize $E$. histolytica antigen $[12,15]$ and the use of the polymerase chain reaction (PCR) to amplify amoebic DNA $[10,13,14]$. More current approaches include the discrimination of E. histolytica, E. dispar and E. moshkovskii by a simultaneous detection using multiplex nested PCR $[18,20]$.

In Malaysia, intestinal parasitic infections (IPIs) including Entamoeba infections are more prevalent in rural areas especially among aboriginal communities compared to urban areas [21-23]. A recent study conducted by Ngui et al. (2011) among communities living in rural areas of Malaysia, showed that $10.2 \%$ of the participants were infected with Entamoeba. Another study showed that the infection rate of Entamoeba in rural communities in Malaysia was 21.0\% [24]. Other local studies which include aboriginal groups reported prevalence ranging from $9.4 \%$ to $18.5 \%[25,26]$. However, these prevalence rates were based on microscopic examination which could not differentiate between $E$. histolytica, E. dispar and E.moshkovskii infections.
In order to avoid unnecessary treatment of individuals with non-pathogenic Entamoeba species, it is important to discriminate these species from the pathogenic E. histolytica [1]. Additionally, there is also a need for simpler and better identification of these infections, not only for diagnostic purposes and care management, where $E$. dispar and E. moshkovskii infected individuals could be treated unnecessarily with antiamoebic chemotherapy, but also for a better understanding of the epidemiology of these parasites in the human population. Within this context, we conducted this study to determine the prevalence of Entamoeba species and the true E. histolytica, E. dispar and E. moshkovskii infections in human faecal samples using molecular techniques.

\section{Methods}

\section{Study area and population}

The present study was carried out from 2009 to 2011 in five rural villages, namely Pos Iskandar $\left(102.65^{\circ} \mathrm{E}\right.$ longitude, $3.06^{\circ} \mathrm{N}$ latitude), Sungai Koyan $\left(101.63^{\circ} \mathrm{E}\right.$ longitude, $4.25^{\circ} \mathrm{N}$ latitude), Sungai Bumbun $\left(101.42^{\circ} \mathrm{E}\right.$ longitude, $2.85^{\circ} \mathrm{N}$ latitude), Bukit Serok (102.82 ${ }^{\circ} \mathrm{E}$ longitude, $2.91^{\circ} \mathrm{N}$ latitude) and Sungai Layau $\left(104.10^{\circ} \mathrm{E}\right.$ longitude, $1.53^{\circ} \mathrm{N}$ latitude) (Figure 1). In brief, the villages are inhabited by members of the indigenous ethnic groups. Each village has a small population and the number of residents in each village is estimated to be 80 to 100 inhabitants. They live in deprived circumstances where overcrowding, poor environmental sanitation, low levels of education and poor provision of safe water are widespread. Although provisions of basic facilities are provided by local authorities, most of them could not afford to pay their monthly utility bills leading to the termination of water supplies. Therefore, rivers located adjacent to the village remain their main source of water for domestic needs such as drinking, cooking, bathing and washing clothes. The condition of the surrounding environment of the village is also generally poor with limited provision of latrine facilities therefore encouraging defecation in and around bushes or nearby rivers. Children usually defecate indiscriminately around their houses without parental supervision. Cats, dogs and poultry are the most common domestic animals. Most of these domestic animals are left to roam freely within the village and were observed to defecate in the surrounding property of their owners. The villagers have very close contact with these animals, even sharing food from the same plate with them.

\section{Consent, sample collection and laboratory procedures}

The study protocol was approved by the Ethics Committee of the University of Malaya Medical Centre, Malaysia (UMMC; MEC Ref. No. 824.11). Before sample collection, an oral briefing to describe the objectives and methodology of the study was given to the participants 


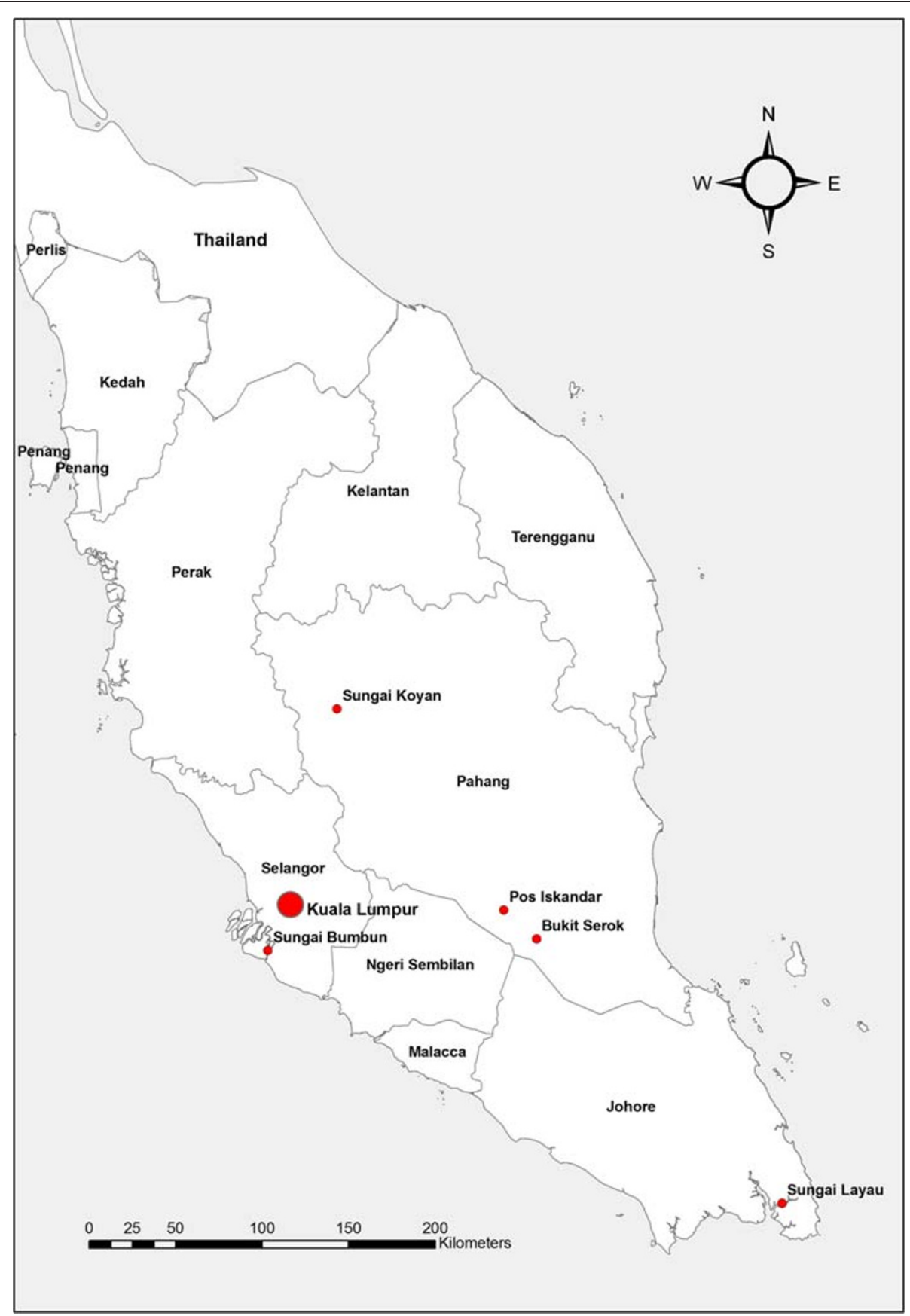

Figure 1 Location of the sampling areas.

by the investigator. Their consent was taken either in written form (signed) or verbally followed by thumb prints (for those who were illiterate) or their parents/ guardians (on behalf of their children) after which prelabeled plastic containers for faecal collection were handed out to all participants. Their ability to recognize their names was checked.

The filled containers were collected on the following day. The fresh faecal samples were stored at ambient temperature and transferred to the laboratory within 24 hours post-collection. Upon arrival at the laboratory, the samples were preserved in $2.5 \%$ potassium dichromate and kept at $4^{\circ} \mathrm{C}$ until further analysis. The faecal samples were processed by direct wet smear and formalin ethyl acetate sedimentation technique followed by iodine staining and examined via microscopy for the presence of Entamoeba species and other intestinal parasites. Microscopically positive samples for Entamoeba species 
cysts were further characterized using a molecular technique.

\section{Extraction of entamoeba genomic DNA}

DNA was extracted from microscopically positive faecal samples using PowerSoil ${ }^{\circledR}$ DNA Isolation Kit (Mo Bio, cat. no. 12888-100, CA, USA) according to the manufacturer's instructions. Briefly, approximately 0.2 to $0.3 \mathrm{~g}$ of faecal sample was added into the PowerBead Tube ${ }^{\circledR}$ followed by incubation at $70^{\circ} \mathrm{C}$ for 10 minutes with the presence of cell lysis and disruption agent provided in the kit. Afterwards, homogenization and cell lysis procedure of the faecal sample were completed by mechanical shaking (vortexing) using MO BIO Vortex Adapter (MO BIO, cat. no. 13000-V1). The extracted DNA was stored at $-20^{\circ} \mathrm{C}$ until required for PCR amplification.

\section{Nested polymerase chain reaction (nested-PCR)}

Nested PCR targeting 16S-like ribosomal RNA gene was used to genetically characterize E. histolytica, E. dispar and E. moshkovskii according to Que and Reed (1991) [27]. Primary PCR for the detection of Entamoeba genus used forward primer E-1 (5'-TAA GAT GCA GAG CGA AA-3') and reverse primer E-2 (5'-GTA CAA AGG GCA GGG ACG TA-3'). Control samples without DNA (DNase free water, Sigma Cat. no. W4502) and with Entamoeba species genomic DNA (positive control) were included in each PCR run. The PCR was carried out in a $25 \mu$ volume with the final mix containing 10x PCR buffer, $1.25 \mathrm{mM}$ dNTPs, $25 \mathrm{mM} \mathrm{MgCl}_{2}$, 10 pmole of each primer, $2.5 \mathrm{U}$ of Taq polymerase and $2.5 \mu \mathrm{l}$ of DNA template. The sample was heated to $96^{\circ} \mathrm{C}$ for $2 \mathrm{~min}$, followed by 30 cycles of $92^{\circ}$ $\mathrm{C}$ for $1 \mathrm{~min}$ (denaturing), $56^{\circ} \mathrm{C}$ for $1 \mathrm{~min}$ (annealing), $72^{\circ} \mathrm{C}$ for $1 \mathrm{~min} 30 \mathrm{~s}$ (extension) and a final extension at $72^{\circ} \mathrm{C}$ for $7 \mathrm{~min}$.

Subsequently, the primary PCR products were subjected to secondary PCR for Entamoeba species-specific characterization. Amplification was achieved using primer sets EH-1 (5'-AAG CAT TGT TTC TAG ATC TGA G-3') and EH-2 (5'-AAG AGG TCT AAC CGA AAT TAG-3') to detect E. histolytica (439 bp); ED-1 (5'-TCT AAT TTC GAT TAG AAC TCT-3') and ED-2 (5'-TCC CTA CCTATT AGA CAT AGC-3') to detect E. dispar (174 bp); Mos-1 (5'-GAA ACC AAG AGT TTC ACA AC-3') and Mos-2 (5'-CAA TAT AAG GCT TGG ATG AT-3') to detect E. moshkovskii (553 bp) [14] (Khairnar and Parija, 2007). The secondary amplification reagent concentrations were similar to the first PCR except that $2.5 \mu \mathrm{l}$ of primary PCR product was added instead of genomic DNA template.

The secondary PCR had a similar cycling condition except that the annealing temperature $\left(48^{\circ} \mathrm{C}\right.$ instead of $56^{\circ} \mathrm{C}$ ) and extension duration $(1 \mathrm{~min}$ instead of $1 \mathrm{~min}$ $30 \mathrm{sec})$ were modified. In both amplifications, samples were incubated in the MyCycler thermal cycler (BioRad, Hercules, USA). PCR generated amplicons of $174 \mathrm{bp}$ for E. dispar, $439 \mathrm{bp}$ for E. histolytica and $553 \mathrm{bp}$ for $E$. moshkovskii were subjected to electrophoresis in $2 \%$ agarose gels at $100 \mathrm{~V}$ for $35 \mathrm{~min}$ and visualized in a UV transilluminator after staining with SYBR Safe DNA stain (Invitrogen, USA).

\section{Data analysis}

Detection of Entamoeba species was determined on the basis of morphological characteristics of the cysts under microscopy. The average cyst size is $12 \mu \mathrm{m}$ but ranges from $10-20 \mu \mathrm{m}$ in diameter. The data entry and analysis was carried out using the SPSS software (Statistical Package for the Social Sciences) program for Windows version 17 (SPSS, Chicago, IL, USA). Qualitative data were estimated and presented as frequencies and percentage. The prevalence and 95\% confidence intervals (CIs) were calculated for each parasite. Associations between proportions were explored using Chi-Square $X^{2}$ (test) and a $P$ value of $<0.05$ was considered indicative of a statistically significant difference.

\section{Results}

\section{Prevalence of Entamoeba infection via microscopy}

A total of 426 samples were collected and 75 (17.6\%; $95 \% \mathrm{CI}=14.0-21.2 \%)$ samples were microscopically positive for Entamoeba cysts, either singly or in combination with other intestinal parasites (Table 1). The overall prevalence of other intestinal parasites has been published (Ngui et al. 2011). Infection was more prevalent in females $(19.1 \%$; $95 \% \mathrm{CI}=14.0-24.2 \%)$ compared to males (15.9\%; 95\% CI =10.8-21.0\%), however, it was not statistically significant (data not shown). Similarly, more adults $(23.9 \%$; $95 \% \mathrm{CI}=16.0-31.8 \%)$ were found to be positive for Entamoeba infections compared to children (15.3\%; 95\% CI $=11.3-19.3 \%)$, but this difference was also not significant $(P>0.05)$. Higher prevalence rates were recorded in Pos Iskandar (29.2\%), followed by Sungai Koyan (22.2\%), Sungai Bumbun (16.8\%), Bukit Serok (15.3\%) while Sungai Layau (5.6\%) had the least (Table 2).

\section{Nested PCR}

Of the 75 microscopy-positive samples, 52 (69.3\%) samples were successfully amplified and characterized the Entamoeba species on the basis of its amplicons size using nested PCR. Additionally, 351 microscopynegative samples were also examined using PCR and the results confirmed that these samples were negative for the Entamoeba infection. Every sample that was negative by PCR (23 samples) but positive by microscopy, was retested by PCR, and each was again found to be PCR negative. Of the 52 PCR positive results, $E$. histolytica 
Table 1 Overall prevalence of Entamoeba infection in the studied populations as determined by microscopy according to gender and age groups $(\mathbf{N}=426)$

\begin{tabular}{lcccc}
\hline Characteristics & $\mathbf{N}$ & $\mathbf{n}$ & $\mathbf{\%}$ & $\mathbf{9 5 \%} \mathbf{~ C l}$ \\
\hline Gender & & & & \\
$\quad$ Male & 201 & 32 & 15.9 & $10.8-21.0$ \\
$\quad$ Female & 225 & 43 & 19.1 & $14.0-24.2$ \\
Age groups & & & & \\
$\quad$ Children & 313 & 48 & 15.3 & $11.3-19.3$ \\
$\quad$ Adults & 113 & 27 & 23.9 & $16.0-31.8$ \\
Total (Overall prevalence) & $\mathbf{4 2 6}$ & $\mathbf{7 5}$ & $\mathbf{1 7 . 6}$ & $\mathbf{1 4 . 0 - 2 1 . 2}$ \\
\hline
\end{tabular}

$\mathrm{N}$ : Total number examined; n: Entamoeba positive by microscopy;\%: Percentage; $95 \% \mathrm{Cl}$ : Confidence Interval.

infection $(75.0 \% ; 39 / 52)$ appeared to be the most predominant, followed by E. dispar $(30.8 \% ; 18 / 52)$ and $E$. moshkovskii (5.8\%; 3/52). Of these, 33 (63.5\%) were shown to contain only E. histolytica, 10 (19.2\%) contained only $E$. dispar and $3(5.8 \%)$ contained only $E$. moshkovskii. Mixed infection with E. histolytica and E. dispar was found in 6 (11.5\%) samples (Table 3).

Pos Iskandar recorded the highest prevalence of $E$. histolytica (53.8\%; 28/52), followed by Sungai Layau (5.8\%; $3 / 52$ ) and $2(3.8 \%)$ samples each from Sungai Koyan, Sungai Bumbun and Bukit Serok. As for E. dispar, the highest prevalence was detected in Sungai Bumbun (13.5\%; 7/52), followed by Sungai Koyan (7.8\%; 4/52), Bukit Serok $(5.8 \% ; 3 / 52)$ and $2 \%$ each $(1 / 52)$ for Pos Iskandar and Sungai Layau. Meanwhile, E. moshkovskii was only found in two villages with Bukit Serok (3.8\%; $2 / 52$ ) recorded as having the highest prevalence rate followed by one infection in Sungai Bumbun.

\section{Discussion}

The present study reported an overall prevalence of Entamoeba species as determined by microscopy as $17.6 \%$ (75/426). In Malaysia, previous studies have also reported high prevalence of Entamoeba infection with prevalence rates ranging from $9.4 \%$ to $21.0 \%$ among

\begin{tabular}{|c|c|c|c|c|c|}
\hline \multirow[t]{2}{*}{ Location (s) } & \multirow{2}{*}{$\frac{\text { No. }}{\text { Examined }}$} & \multicolumn{2}{|c|}{ Microscopy } & \multicolumn{2}{|c|}{ PCR assay } \\
\hline & & $\mathrm{n}$ & $\%$ & $\mathrm{n}$ & $* \%$ \\
\hline Pos Iskandar & 113 & 33 & 29.2 & 29 & 87.9 \\
\hline Sungai Koyan & 18 & 4 & 22.2 & 4 & 100 \\
\hline Sungai Bumbun & 107 & 18 & 16.8 & 8 & 44.4 \\
\hline Bukit Serok & 99 & 15 & 15.3 & 7 & 46.7 \\
\hline Sungai Layau & 89 & 5 & 5.6 & 4 & 80.0 \\
\hline Total & 426 & 75 & 17.6 & 52 & 69.3 \\
\hline
\end{tabular}

$\mathrm{n}$ : Number positive; * Based on the number positive by microscopy. rural communities [23-26,28]. In contrast, the most recent study among rural communities in Malaysia demonstrated $10.2 \%$ of the participants were infected with Entamoeba species [23]. The high prevalence of Entamoeba infection may be due to the transmission and pathogenesis as well as other risk factors which favor the persistence of this infection. Given its faecaloral route, habits related to eating, defecation, personal hygiene, cleanliness and level of education may have an impact on the prevalence rates. The findings of this study confirmed a trend of high risk of infection with Entamoeba species among the rural population as shown by other local studies [21-23,25], where prevailing poverty, poor socioeconomic condition, low standards of sanitation and hygiene and lack of education attainment may contribute to high prevalence of Entamoeba infection.

Additionally, the use of untreated river water as a source for household needs could also lead to the increase in the transmission of Entamoeba infection. A study in Thailand conducted to determine the occurrence of Entamoeba species in water samples using molecular techniques has indicated that water is a possible source for transmission of Entamoeba to humans [29]. From our personal observation, the majority of the households have no toilet facilities. They often defecate indiscriminately in the bushes and nearby river at the back of their houses. These water sources may be highly polluted especially in rainy seasons, by rain runoff contaminated with cysts of parasites from human faeces. Another possible source of infection could also be from the consumption of water contaminated with Entamoeba cysts from faeces of infected wild or domestic animals as they may come to the river bank to drink and at the same time defecate in or near the river. This situation is further aggravated as the drinking of unboiled water is a common practice among this community. Therefore, these communities should be given health education and made aware of the danger of drinking unboiled or improperly boiled untreated water.

Our molecular technique showed that E. histolytica (75.0\%) was found to be the most common species detected in this study, followed by E. dispar (30.8\%) and E. moshkovskii (5.8\%). Similarly, the only available species-specific study of Entamoeba species conducted in Malaysia found that E. histolytica (13.2\%) was more prevalent compared to E. dispar (5.6\%) [28]. Interestingly, the high prevalence of E. histolytica in the present study was in contrast to the worldwide distribution of Entamoeba species, which indicated that E. dispar is perhaps 10 times more common than E. histolytica $[1,2,30]$, however, the local prevalence may vary significantly, thus necessitating the assessment of prevalence in different geographical regions. Similar observation 
Table 3 Prevalence of E. histolytica, E. dispar and E. moshkovskii infections as determined by nested PCR in microscopically positive faecal samples according to locations

\begin{tabular}{|c|c|c|c|c|c|c|c|c|c|}
\hline \multirow[t]{2}{*}{ Location (s) } & \multirow[t]{2}{*}{ PCR Positive } & \multicolumn{2}{|c|}{ E. histolytica only } & \multicolumn{2}{|c|}{ E. dispar only } & \multicolumn{2}{|c|}{ E. moshkovskii only } & \multicolumn{2}{|c|}{ E. histolytica + E. dispar } \\
\hline & & $\mathrm{n}$ & $\%$ & $\mathrm{n}$ & $\%$ & $\mathrm{n}$ & $\%$ & $\mathrm{n}$ & $\%$ \\
\hline Pos Iskandar & 29 & 28 & 96.6 & 1 & 3.4 & 0 & 0 & 0 & 0 \\
\hline Sungai Koyan & 4 & 0 & 0 & 2 & 50.0 & 0 & 0 & 2 & 50.0 \\
\hline Sungai Bumbun & 8 & 0 & 0 & 5 & 62.5 & 1 & 12.5 & 2 & 25.0 \\
\hline Bukit Serok & 7 & 2 & 28.6 & 1 & 14.3 & 2 & 28.6 & 2 & 28.6 \\
\hline Sungai Layau & 4 & 3 & 75.0 & 1 & 25.0 & 0 & 0 & 0 & 0 \\
\hline Total & 52 & 33 & 63.5 & 10 & 19.2 & 3 & 5.8 & 6 & 11.5 \\
\hline
\end{tabular}

also reported that $70.8 \%$ of patients were infected with E. dispar, compared to $4.5 \%$ of E. histolytica and $61.8 \%$ of E. moshkovskii in Australia [10]. A study in Brazil also showed that the prevalence of $E$. dispar (90\%) was more frequent compared to E. histolytica (10\%) among infected individuals [5]. A study in India also showed parallel findings, where $49.5 \%$ patients were infected with E. dispar and only $7.4 \%$ with E. histolytica [18]. Likewise, a study in the Netherlands also found $91.2 \%$ microscopic positive samples were identified as E. dispar while $6.7 \%$ were E. histolytica by PCR [31]. In Canada, $97.1 \%$ of the examined samples contained $E$. dispar compared to $2.9 \%$ of E. histolytica by both PCR and ELISA assay [16].

To the best of our knowledge, the detection E. moshkovskii $(5.8 \%)$ in this study was the first to be reported in Malaysia. Cases of humans infected with E. moshkovskii have been reported sporadically from different parts of the world including Thailand [6], India [9,18,20], Bangladesh [8,32] and Australia [10]. A study in Bangladesh highlighted that infection with E. moshkovskii was common in children aged 2 to 5 years [8] while a study in India found that E. moshkovskii infection was associated with dysentery [9]. In our study, it was noted that all individuals infected with $E$. moshkovskii were children and were asymptomatic. Although amoebic liver abscess (65\%) has been documented in patients admitted to an urban hospital in Malaysia [33], information from rural communities is not available as this infection can only be confirmed in a hospital setup. Therefore, future investigation which includes the clinical impact of $E$. moshkovskii and other Entamoeba species is imperative for a better understanding of a true pathogenic potential of E. moshkovskii.

Although every negative PCR sample was retested by PCR, each was again found to be negative. This result can potentially be explained by the presence of faecal inhibitor substances which were not completely eliminated prior to PCR reaction. Further study to optimize the reduction of these inhibitors is necessary during the extraction process in order to increase PCR sensitivity. It is also possible that the samples which were detected by microscopy but not PCR may belong to other Entamoeba species such as E. coli, E. hartmanni and E. polecki, or the contained a low number of parasites, which fell below the PCR detection limit. Therefore, a more sensitive method such as Real-Time PCR and employing primers for all Entamoeba species should be considered in future study. The failure to amplify samples could also be due to the fact that samples may contain only trophozoites that could have degenerated with time. Several studies have confirmed that the presence of Entamoeba cysts in the faecal samples, in contrast to trophozoites, somewhat increase the chances of the PCR assay $[10,34]$.

\section{Conclusion}

Molecular techniques are indeed promising tools for epidemiological studies, particularly in discriminating the pathogenic from the non-pathogenic species of the Entamoeba species. This study reports for the first time the identification of E. moshkovskii in human faecal samples from Malaysia. Since all of the infected participants with E. moshkovskii including those infected with the other two species were asymptomatic, further investigations are needed to determine the true pathogenic potential of these three species.

\section{Competing interests}

The authors have declared that no competing interests exist.

\section{Authors' contributions}

RM, YALL, LYL and JI planned and designed the protocols. RN, LA and SAF conducted the field study the study programme, including the collections of stool samples and data from the questionnaire interviews, as well as the management of collected data. RM, YALL, LYL and Jl supervised all the laboratory work. RN, LA and SAF carried out the data analysis and interpretation. RN, LA, YALL and RM prepared the first draft of the manuscript and all authors revised the manuscript critically. All authors read and approved the final version of the manuscript.

\section{Financial support}

This research work was funded by the High Impact Research Grant (E0005020001), University of Malaya Research Grant (RG221-10HTM) and Postgraduate Research Fund (PV024/2011B) from University of Malaya. The funders had no role in study design, data collection and analysis, decision to publish or preparation of the manuscript. 


\section{Acknowledgments}

The authors are very grateful to Mr. Saidon Ishak and Mr. Abdul Hamid for their assistance during sample collection. Most importantly, the authors would like to thank all the villages who have voluntarily participated in this study.

Received: 16 July 2012 Accepted: 17 August 2012

Published: 4 September 2012

\section{References}

1. WHO: World Health Organization/Pan American Health Organization/ UNESCO report of a consultation of experts on amoebiasis. Wkly Epidemiol Rec WHO 1997, 72:97-99.

2. Markell EK, John DJ, Krotoski WA: Lumen dwelling protozoa. 8th edition. Philadelphia, USA: WB Saunders; 1999.

3. Delialioglu N, Aslan G, Ozturk C, Ozturhan H, Sen S, Emekdas G: Detection of Entamoeba histolytica antigen in stool samples in Mersin, Turkey. J Parasitol 2008, 94:530-532.

4. Salvioli $L$, Bundy DAP, Tomkin A: Intestinal parasitic infections. Trans $R$ SoC Trop Med Hyg 1992, 86:353-354.

5. Braga L, Gomes ML, Silva MW, Paiva C, Sales A, Mann BJ: Entamoeba histolytica and Entamoeba dispar infections as detected by monoclonal antibody in an urban slum in Fortaleza, Northeastern Brazil. Rev Soc Bras Med Trop 2001, 34:467-471.

6. Hamzah Z, Petmitr S, Mungthin M, Leelayoova S, ChavalitshewinkoonPetmitr P: Differential detection of Entamoeba histolytica, Entamoeba dispar and Entamoeba moshkovskii by a single-round PCR Assay. J Clin Microbiol 2006, 44:3196-3200.

7. Clark CG, Diamond LS: The Laredo strain and other 'Entamoeba histolytica like' amoebae are Entamoeba moshkovskii. Mol Biochem Parasitol 1991, 46:11-18.

8. Ali IKM, Hossain MB, Roy S, Ayeh-Kumi P, Petri JWA, Haque R, Clark CG: Entamoeba moshkovskii infections in children, Bangladesh. Emerg Infect Dis Emerging 2003, 9:580-584.

9. Parija SC, Khairnar K: Entamoeba moshkovskii and Entamoeba disparassociated infections in Pondicherry, India. J Health Popul Nutr 2005 23:292-295.

10. Fotedar R, Stark D, Beebe N, Marriot D, Ellis J, Harkness J: PCR detection of Entamoeba histolytica, Entamoeba dispar and Entamoeba moshkovskii in stool samples from Sydney, Australia. J Clin Microbiol 2007, 45:1035-1037.

11. Al-Harthi SA, Jamjoon MB: Diagnosis and differentiation of Entamoebo infection in Makkah Al Mukarramah using microscopy and stool antigen detection kits. World J Med Sci 2007, 2:15-20.

12. Wonsit R, Thammapalerd N, Tharavanji S, Radomyos P, Bunnarg D: Enzymelinked immunorsorbent assay based on monoclonal and polyclonal antibodies for the detection of Entamoeba histolytica antigens in faecal specimens. Trans Roy Soc Trop Med Hyg 1992, 86:166-169.

13. Katzwinkel-Wladarsch $\mathrm{S}$, Loscher $\mathrm{T}$, Reider $\mathrm{H}$ : Direct amplification and differentiation of pathogenic and non-pathogenic Entamoeba histolytica DNA from stool specimen. Am Soc Trop Med Hyg 1994, 51:115-118.

14. Troll H, Marti H, Weiss N: Simple differential detection of Entamoeba histolytica and Entamoeba dispar in fresh stool specimens by sodium acetate-acetic acid-formalin concentration and PCR. J Clin Microbiol 1997, 35:1701-1705.

15. Yvonne CW, Crandal I, Kain CK: Development of monoclonal antibodies which specifically recognize Entamoeba histolytica in preserved stool samples. J Clin Microbiol 2001, 39:716-719.

16. Gonin P, Louise T: Detection and differentiation of Entamoeba histolytica and Entamoeba dispar isolates in clinical samples by PCR and enzymelinked immunosorbent assay. J Clin Microbiol 2003, 41:237-241.

17. Redondo RB, Mendez LGM, Baer G: Entamoeba histolytica and Entamoeba dispar: differentiation by enzyme-linked immunosorbent assay (ELISA) and its clinical correlation in pediatric patients. Parasitol Latinoam 2006, 6:37-42.

18. Khairnar K, Parija SC: A novel nested multiplex polymerase chain reaction (PCR) assay for differential detection of Entameoba histolytica, $E$. moshkovskii and E. dispar DNA in stool samples. BMC Microbiol 2007, 7:47.

19. Zeehaida M, Wan Nor Amilah WAW, Amry AR, Hassan S, Sarimah A, Rahmah N: A study on the usefulness of Techlab Entamoeba histolytica II antigen detection ELISA in the diagnosis of amoebic liver abscess (ALA) at Hospital
Universiti Sains Malaysia(HUSM), Kelantan, Malaysia. Trop Biomed 2008, 25:209-216.

20. Parija SC, Garg A, Puspha K, Khairnar K, Priya T: Polymerase chain reaction of diagnosis of intestinal amebiasis in Puducherry. Indian J Gastroenterol 2010, 29:140-142.

21. Norhayati M, Fatmah MS, Yusof S: Intestinal parasitic infections in man: A review. Med J Malaysia 2003, 58:2-10.

22. Lim YAL, Romano N, Colin N, Chow SC, Smith HV: Intestinal parasitic infections amongst Orang Asli (indigenous) in Malaysia: Has socioeconomic development alleviated the problem? Trop Biomed 2009, 26:110-122.

23. Ngui R, Saidon I, Chow SK, Rohela M, Lim YAL: Prevalence and risks factors of intestinal parasitism in rural and remote West Malaysia. PLoS Negl Trop Dis 2011, 5:e974.

24. Nor A, Ashley S, Albert J: Parasitic infection in human communities living on the fringes of the Crocker Range Park Sabah, Malaysia. In ASEAN Review of Biodiversity and Environmental Conservation (ARBEC).; 2003. http://www.arbec.com.my/pdf/art11janmar03.pdf.

25. Rajeswari B, Sinniah B, Hussein H: Socioeconomic factor associate with intestinal parasites among children living in Gombak, Malaysia. Asia Pac J Publ Health 1994, 7:21-25.

26. Hakim SL, Gan CC, Malkit K, Azian MN, Chong CK, Shaari N, Zainuddin W Chin CN, Sara Y, Lye MS: Parasitic infections among Orang Asli (aborigine) in the Cameron Highlands, Malaysia. Southeast Asian J Trop Med Publ 2007, 38:415-419.

27. Que X, Reed SL: Nucleotide sequence of a small subunit ribosomal RNA (16S like rRNA) gene from Entamoeba histolytica: differentiation of pathogenic from non pathogenic isolates. Nucleic Acids Res 1991, 19:5438.

28. Noor Azian MY, San YM, Gan CC, Yusri MY, Nurulsyamzawaty Y, Zuhaizam AH, Maslawaty MN, Norparina I, Vythilingam I: Prevalence of intestinal protozoa in an aborigine community in Pahang, Malaysia. Trop Biomed 2006, 24:55-62.

29. Sukprasert S, Rattaprasert P, Hamzah Z, Shipin OV, ChavalitshewinkoonPetmitr P: PCR detection of Entamoeba spp from surface and waste water samples using genus-specific primers. Southeast Asian J Trop Med Publ 2008, 39:6-9.

30. Petri JWA, Haque R, Lyerly D, Vines R: Estimating the impact of amoebiasis on health. Parasitol Today 2000, 16:320-321.

31. Visser LG, Verweij JJ, Van Esbroeck M, Edeling WM, Clerinx J, Polderman AM: Diagnostic methods for differentiation of Entamoeba histolytica and Entamoeba dispar in carriers: performance and clinical implications in a non-endemic setting. Int J Med Microbiol 2006, 296:397-403.

32. Haque R, Ali IKM, Clark CG, Petri JWA: A case report of Entamoeba moshkovskii infection in a Bangladeshi child. Parasitol Int 1998, 47:201-202.

33. Farhana F, Jamaiah I, Rohela M, Abdul-Aziz NM, Nissapatorn V: A ten year (1999-2008) retrospective study of amoebiasis in University Malaya Medical Centre (UMMC), Kuala Lumpur, Malaysia. Trop Biomed 2009, 26:262-266

34. Kebede A, Verweij JJ, Endeshaw T, Messele T, Tasew G, Petros B, Polderman AM: The use of real-time PCR to identify Entamoeba histolytica and E. dispar infections in prisoners and primary-school children in Ethiopia. Ann Trop Med Parasitol 2004, 98:43-48.

doi:10.1186/1756-3305-5-187

Cite this article as: Ngui et al:: Differentiating Entamoeba histolytica, Entamoeba dispar and Entamoeba moshkovskii using nested polymerase chain reaction (PCR) in rural communities in Malaysia. Parasites \& Vectors 2012 5:187. 